\title{
Cultura autóloga de células-tronco mesenquimais de tecido adiposo para o tratamento de rítides faciais
}

\section{Autologous mesenchymal stem cells culture from adipose tissue for treatment of facial rhytids}

\author{
César Claudio-da-Silva, tCBC-RJ1 ; Leandra Santos Baptista²; Rosana Bizon Vieira Carias 3 ; Hélio da Cunha Menezes Neto3; \\ RADOVAN BOROJEVIC ${ }^{2}$
}

\section{RES U M O}

\begin{abstract}
Objetivo: Testar o efeito das células tronco mesenquimais (CTM) de tecido adiposo no preenchimento cutâneo de rítides na região naso-labial. Métodos: Foram coletados $50 \mathrm{cc}$ de gordura da região infra-umbilical e $20 \mathrm{~mL}$ de sangue periférico de 15 voluntárias do sexo feminino para obtenção das CTM e de plasma autólogo, respectivamente. As voluntárias foram agrupadas de acordo com as estratégias de injeções intra-dérmicas: grupo (1) somente o ácido hialurônico; grupo (2) somente as CTM; grupo (3) CTM associadas ao ácido hialurônico. Tratando-se de um estudo prospectivo e qualitativo o acompanhamento das voluntárias era mensal através de fotografias. Resultados: No grupo (1) foi observado um efeito de preenchimento imediato ao contrário do grupo (2) onde o efeito de preenchimento pleno foi alcançado aproximadamente após dois meses. No grupo (3) o preenchimento ocorreu de maneira mais efetiva e também progressiva, devido à combinação dos efeitos de curto e de longo prazo gerados pelo ácido hialurônico e pelas CTM, respectivamente. Conclusão: As CTM quando associadas ao ácido hialurônico foram capazes de promover o preenchimento de sulcos profundos, com melhora progressiva do tônus da pele e diminuição das linhas de expressão.
\end{abstract}

Descritores: Células-tronco mesenquimais. Tecido adiposo.Rejuvenescimento.

\section{INTRODUÇÃO}

A literatura proporciona uma variedade de relatos com diferenças entre os graus de sucesso e falência do procedimento de lipoescultura. O sucesso do procedimento depende diretamente das técnicas de coleta, limpeza e reinjeção do material ${ }^{1}$. Porém ainda não existe um protocolo padrão que defina a melhor maneira de processamento da gordura, para um enxerto de longo prazo independente da área injetada ${ }^{2}$.

Muitos médicos acreditam que a sobrevivência dos adipócitos é um dos principais fatores que interferem diretamente no sucesso do enxerto 3 . Porém, a fração estromal do tecido adiposo é constituída de préadipócitos, células endoteliais, macrófagos, fibroblastos ${ }^{4}$ e também por células tronco mesenquimais (CTM), que quando apropriadamente estimuladas, dão origem a osso, cartilagem, e adipócitos 5,6. Uma célula-tronco adulta é definida por várias propriedades, incluindo a sua habilidade de "auto-renovação". Quando uma célula-tronco é estimulada a se dividir, ela pode dar origem a célulasfilhas mais comprometidas a formar um tipo celular do tecido em que reside. Outras células filhas podem permanecer no estágio de células-tronco, podendo ainda se dividir inúmeras vezes? ${ }^{7}$.

Estratégias regenerativas baseadas no uso de CTM do tecido adiposo são uma grande promessa para procedimentos médicos de aumento de tecidos moles, pois oferecem a possibilidade de um preenchimento em longo prazo $^{8}$. Foi mostrado recentemente que a associação de CTM ao enxerto de gordura visando o aumento de seios promove resultados clínicos satisfatórios sem maiores complicações ${ }^{9}$.

Além do uso combinado a enxerto de tecidos, as CTM podem ser associadas a fatores de crescimento, e/ou a arcabouços (sintéticos ou biógenos), em um processo chamado de bioengenharia tecidual. O ácido hialurônico é um polissacarídeo importante, sendo o principal elemento da matriz extracelular dos tecidos fetais, e presente nos adultos como elemento estrutural na pele e tecido conjuntivo. Também promove migração e proliferação celular, e sua rápida substituição tecidual in vivo pelo colágeno, faz desse polissacarídeo um ótimo candidato para preenchimento de tecido mole ${ }^{10}$.

Trabalho realizado no Serviço de Cirurgia Plástica do Hospital Universitário Clementino Fraga Filho e na Excellion Serviços Biomédicos. 1. Professor Adjunto do Departamento de Cirurgia Geral, Serviço de Cirurgia Plástica, Hospital Universitário Clementino Fraga Filho, UFRJ, RJ Brasil. Membro Titular da SBCP (Sociedade Brasileira de Cirurgia Plástica); 2. Pós-Doutorado, APABCAM, Hospital Universitário Clementino Fraga Filho, UFRJ, RJ - BR; 3. Gerente de Laboratório, Excellion Serviços Biomédicos S/A, RJ-BR; 4. Professor Titular, Instituto de Ciências Biomédicas, UFRJ, RJ - BR. 
O estudo clínico aqui apresentado é baseado na utilização dos recursos da engenharia de tecidos, e envolve a criação de um implante autólogo de CTM associado ao ácido hialurônico para o preenchimento cutâneo de rítides na região naso-labial. Com esta combinação espera-se a formação de uma rede de matriz tridimensional in vivo. Sendo hidrofílica e permeável aos líquidos biológicos ricos em nutrientes, esta rede poderá propiciar um ambiente favorável para o crescimento celular e a produção da nova matriz extracelular, controlando a migração celular para outros locais.

\section{MÉTODOS}

Esse projeto foi aprovado na data de 20/07/2006, pelo Comitê de Ética em Pesquisa do Hospital Pró-CardíaCO (PROCEP), localizado na cidade do Rio de Janeiro - número da portaria: 170, tratando-se de um estudo prospectivo e qualitativo. No período de agosto a setembro de 2006 foram realizadas 15 coletas de gordura da região infra-umbilical em voluntárias do sexo feminino, obtendo-se 50 cc de aspirado. Também foram coletados $20 \mathrm{~mL}$ de sangue periférico para obtenção de plasma autólogo. Todas as voluntárias leram, concordaram e assinaram o termo de consentimento livre e esclarecido. A média e desvio padrão da idade das voluntárias foram de 45,8 \pm 7,48; respectivamente.

Para a coleta do lipoaspirado procedia-se à assepsia e antissepsia seguida da infiltração de 50 cc de solução de lidocaína 0,25\% com adrenalina 1:500.000 nos locais demarcados da região infra-umbilical. O material foi aspirado por meio de seringas com cânulas de $3 \mathrm{~mm}$ de diâmetro, que foram posteriormente seladas e colocadas em decantador por 30 min, para a remoção do conteúdo serossanguíneo. Ao tecido adiposo coletado foram adicionados 10 cc de solução antibiótica e o material foi transportado em ambiente refrigerado até a unidade de processamento.

Para a obtenção das CTM, o tecido adiposo foi processado como previamente descrito ${ }^{5,6}$. As células foram cultivadas em meio de cultura Dulbecco's Modified Eagles Medium (DMEM; LGC, Cotia, SP) suplementado com 10\% soro fetal bovino (Cultilab, Campinas, SP, e antibióticos (100 U/ml de penicilina sódica e $100 \mathrm{mg} / \mathrm{mL}$ de estreptomicina) e mantidas em estufa a $37^{\circ} \mathrm{C}$ com $5 \%$ de $\mathrm{CO}_{2}$ por até uma semana. Dois dias antes da aplicação, as células foram lavadas exaustivamente com solução fisiológica e mantidas em plasma autólogo para eliminação de proteínas fetais bovinas internalizadas ${ }^{11}$.

No dia da aplicação, as células foram dissociadas com solução de tripsina 0,125\% (Gibco BRL, Rockville, MD) e 0,78 mM de EDTA (Invitrogen, Gibco) e ressuspensas em soro fisiológico com ou sem ácido hialurônico (L.E.A, Paris, France) na concentração de 1:2 em um volume final de 0,6 $\mathrm{mL}$. As voluntárias foram agrupadas aleatoriamente de acordo com as estratégias de aplicação: grupo (1) somente ácido hialurônico totalizando quatro pacientes; grupo (2) somente CTM de tecido adiposo totalizando seis pacientes; grupo (3) CTM de tecido adiposo associadas ao ácido hialurônico totalizando cinco pacientes (Tabela 1). Todas as aplicações foram realizadas nos sulcos nasogenianos.

Fotos da face foram capturadas no consultório médico com periodicidade mensal por até um ano. Tratase, portanto, de um estudo qualitativo e prospectivo.

\section{RESULTADOS}

No Grupo (1) foi observado um efeito de preenchimento instantâneo (Figura 1A - D) e a estabilidade do implante variou individualmente, alcançando total reabsorção na voluntária 03, após 12 meses (Figura 1B).

No grupo (2) as CTM se mostraram capazes de gerar melhoras sutis no tônus da região naso-labial (figura $1 \mathrm{E}-\mathrm{H}$ ), mas não de preencher sulcos muito profundos (Figura $1 \mathrm{E}, \mathrm{F})$. No geral, o efeito do preenchimento se manteve por até 10 meses (Figura 1F, H).

No grupo (3) houve uma combinação do efeito imediato do ácido hialurônico com o efeito em longo prazo das CTM. Com isso, o preenchimento do sulco ocorreu de maneira efetiva, e ao invés da reabsorção progressiva observada no grupo (I), a região naso-labial apresentou meIhora do tônus ao longo do tempo (Figura 1। - L). Não houve regressão da melhora em nenhuma das três voluntárias acompanhadas por até um ano (Figura 1J, L).

Não foram observados durante o estudo efeitos colaterais ou reações adversas que pudessem ser atribuídas ao agente de preenchimento e/ou CTM de tecido adiposo.

\section{DISCUSSÃO}

Existem vários tipos de agentes de preenchimento, de origem natural ou sintética, cada qual indicado para

Tabela 1 - Descrição dos produtos de injeção e das voluntárias.

\begin{tabular}{lccl}
\hline & Idade & Data da aplicação Produto Aplicado \\
\hline 01 & 46 & $22 / 08 / 2006$ & Ácido hialurônico \\
02 & 37 & $22 / 08 / 2006$ & Ácido hialurônico \\
03 & 49 & $06 / 09 / 2006$ & Ácido hialurônico \\
04 & 59 & $06 / 09 / 2006$ & Ácido hialurônico \\
05 & 46 & $22 / 09 / 2006$ & Células + Ácido hialurônico \\
06 & 60 & $20 / 10 / 2006$ & Células + Ácido hialurônico \\
07 & 46 & $20 / 10 / 2006$ & Células + Ácido hialurônico \\
08 & 46 & $19 / 06 / 2007$ & Células + Ácido hialurônico \\
09 & 50 & $19 / 06 / 2007$ & Células + Ácido hialurônico \\
10 & 41 & $20 / 07 / 2007$ & Células + Ácido hialurônico \\
11 & 30 & $20 / 10 / 2006$ & Células \\
12 & 48 & $27 / 10 / 2006$ & Células \\
13 & 43 & $03 / 10 / 2006$ & Células \\
14 & 42 & $01 / 12 / 2006$ & Células \\
15 & 44 & $01 / 12 / 2006$ & Células \\
\hline
\end{tabular}



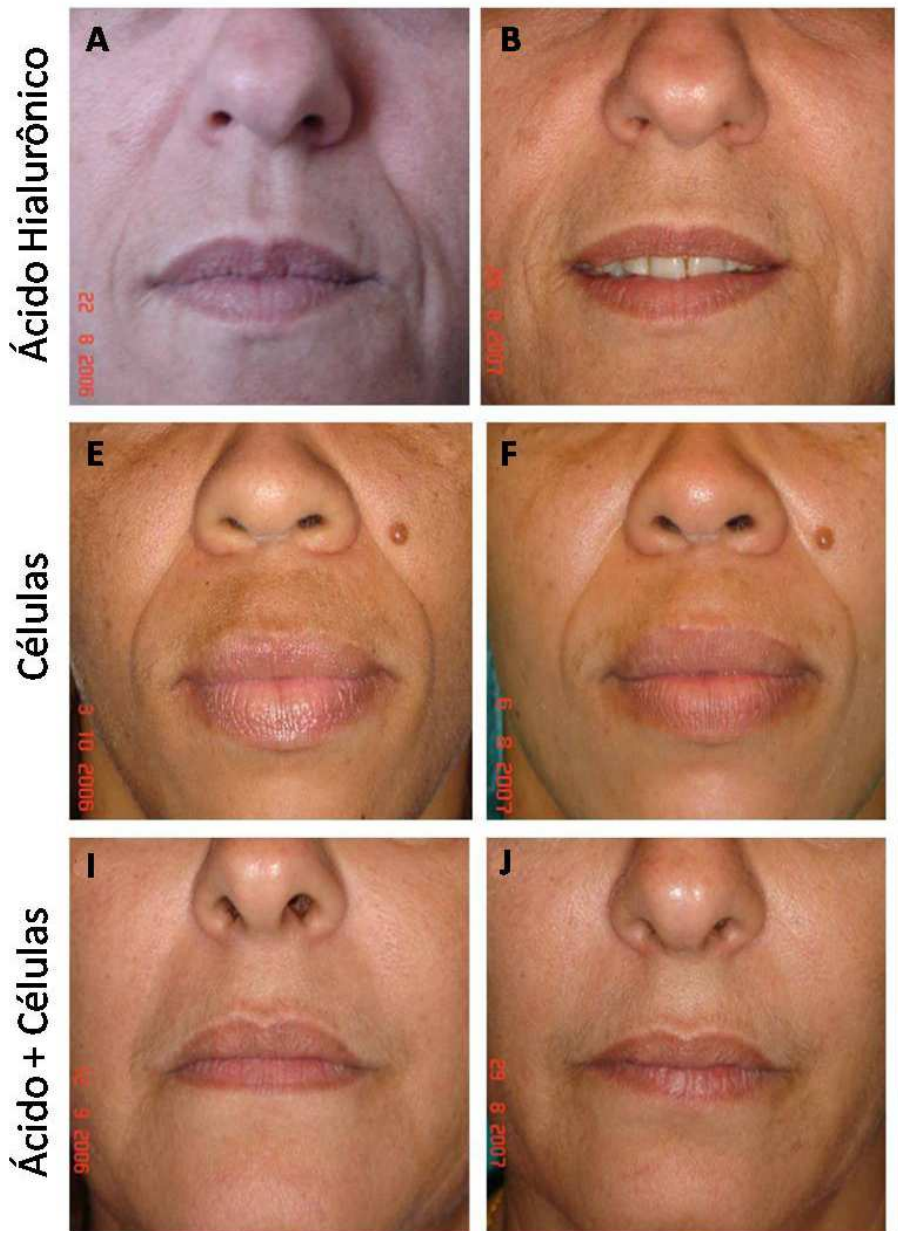
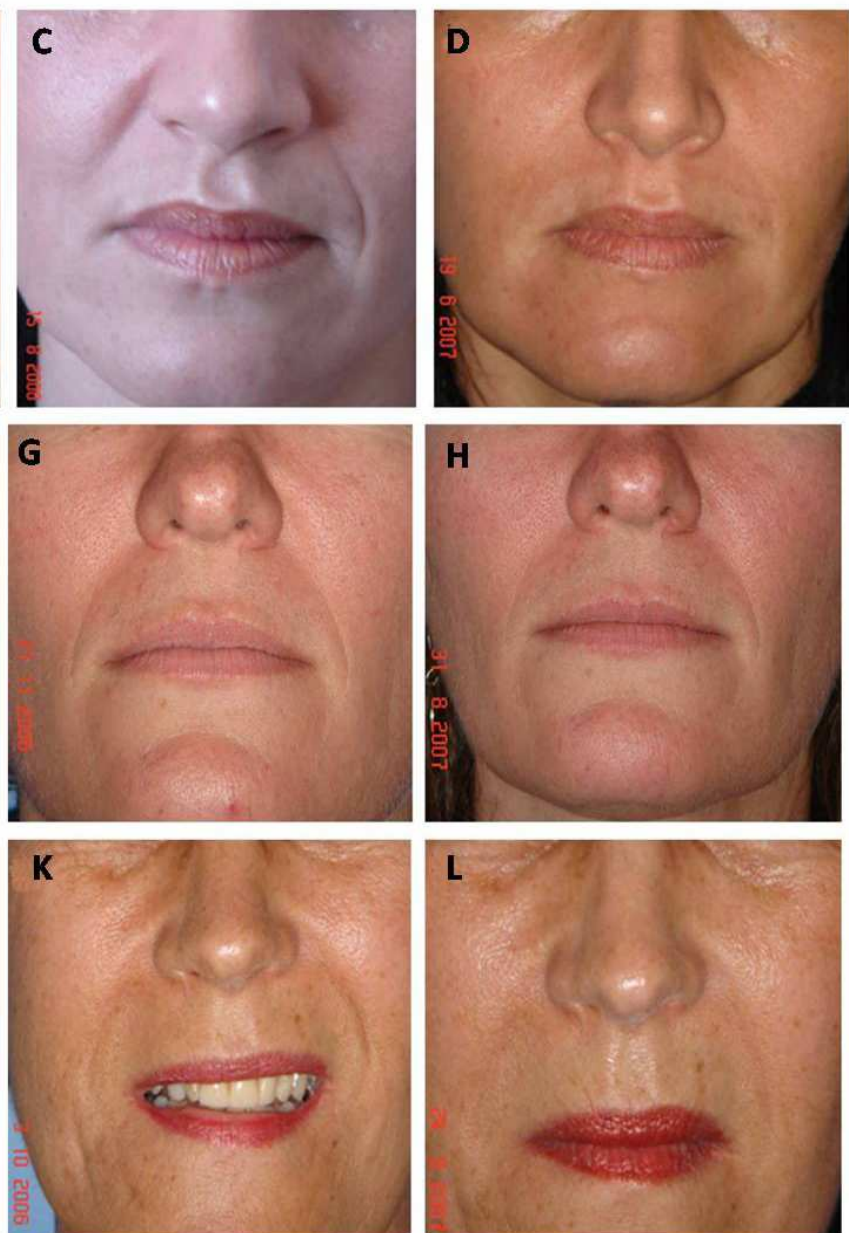

Figura 1 - Pré $(A, C)$ e pós-preenchimento $(B, D)$ com ácido hialurônico das pacientes 03 e 02 em 12 e 10 meses, respectivamente. Pré (E, $G)$ e pós-preenchimento $(F, H)$ com células das pacientes 11 e 14 em 10 e 9 meses, respectivamente. Pré (I, K) e póspreenchimento $(\mathrm{J}, \mathrm{L})$ com células associadas ao ácido hialurônico das pacientes 05 e 06 em12 meses.

um determinado tipo de correção desejada. No caso do preenchimento cutâneo, os agentes mais utilizados são: colágeno, ácido hialurônico, ácido L poli-lático (PLLA), polimetilmetacrilato, e ainda alguns géis a base de hidroxiapatita de cálcio. Alguns materiais sintéticos por serem inertes, não são absorvidos, e por isso proporcionam um preenchimento da derme estável e duradouro. Porém algumas complicações devido a reações inflamatórias crônicas já foram relatadas. O polimetilmetacrilato é responsável por grande parte delas, as quais se apresentaram permanentes ou ainda sem respostas aos tratamentos $^{12}$.

O ácido hialurônico, utilizado neste estudo, é um polissacarídeo natural encontrado na matriz extracelular do tecido conjuntivo, do fluido sinovial e de outros tecidos. A segurança no seu uso advém da sua natureza biocompatível e tem como principal desvantagem sua reabsorção (6 - 12 meses). Uma das estratégias para aumentar sua durabilidade é o cross-linking da molécula que torna o hidrogel mais insolúvel e, por conseguinte menos reabsorvível ${ }^{13}$. Outra estratégia já utilizada na prática clínica é a associação desse ácido com microesferas de dextranômero, uma molécula derivada da glicose, aparentemente estimuladora de síntese de colágeno. Porém, recentemente foi publicado um caso clínico de reação granulomatosa difusa no local de injeção do co-polímero de ácido hialurônico com dextranômero para correção de rítides ${ }^{14}$.

A base para protocolos de terapias celulares consiste no fato de que células saudáveis estimulam o tecido em que foram injetadas para o processo de regeneração ${ }^{15}$. Em preenchimento de rítides e cicatrizes de acne, diversos protocolos utilizando fibroblastos de pele autólogos já foram estabelecidos ${ }^{16-18}$. No caso de terapias celulares com células-tronco, além do efeito estimulatório de regeneração, ensaios clínicos relatam diferenciação das mesmas em células do tecido residente ${ }^{15}$. O tecido adiposo é uma fonte de CTM muito atraente para protocolos de terapias celulares, pois pode ser obtido em grandes quantidades em técnicas de lipoaspiração recorrentes ${ }^{4}$. Em 1999 foi realizado um estudo de preenchimento de rítides utilizando células estromais de tecido adiposo. Os resultados foram bem satisfatórios ${ }^{19}$, mas técnicas de aplicação de gordura total continuam a ser utilizadas ${ }^{1-3}$. Além disso, as CTM de tecido adiposo quando associadas aos enxertos de gordura, conferem maior durabilidade e um expressivo au- 
mento do enxerto ${ }^{9}$, sendo responsáveis pela produção de colágeno in situ, comprovada em modelo animal por análises histopatológicas ${ }^{20}$.

No presente estudo as CTM de tecido adiposo foram utilizadas para o preenchimento de rítides faciais. As
CTM quando associadas ao ácido hialurônico são capazes de preenchimento de sulcos profundos, com melhora progressiva do tônus da pele e diminuição das linhas de expressão, provendo a base para estratégias únicas de regeneração e reparo de tecido mole.

\section{A B S T R A C T}

Objective: To test the effect of mesenchymal stem cells (MSC) from adipose tissue on the dermal filling for nasolabial rhytids correction. Methods: $50 \mathrm{cc}$ of infraumbilical fat and $20 \mathrm{ml}$ of peripheral blood were harvested to isolate MSC and autologous plasma from 15 female volunteers, respectively. The volunteers were grouped in according to the following strategies of intradermal injection: Group (I) only hyaluronic acid; Group (II) only MSC; Group (III) MSC combined with hyaluronic acid. For this qualitative and prospective study photographic monitoring was done monthly. Results: In the group (I) we observed an immediate effect of filling; in the group (II) the effect of filling was reached after approximately two months. In the group (III) filling occurred more efficiently and progressively, probably due to the combination of the short and long-term effects generated by the hyaluronic acid and MSC, respectively. Conclusion: MSC when combined with hyaluronic acid were able to fill in deep folds, with progressive improvement of skin tone and decreasing lines of expression.

Key words: Mesenchimal stem cells. Adipose tissue. Rejuvenation.

\section{REFERENCIAS}

1. Shiffman MA, Mirrafati S. Fat transfer techniques: the effect of harvest and transfer methods on adipocyte viability and review of the literature. Dermatol Surg. 2001; 27(9):819-26.

2. Toledo LS, Mauad R. Fat injection: a 20-year revision. Clin Plast Surg. 2006; 33(1):47-53.

3. Dolsky RL, Newman J, Fetzek JR, Anderson RW. Adipocyte survival. In: Proceedings of the $3^{\text {rd }}$ Annual Scientific Meeting of the American Academy of Cosmetic Surgery and the American Society of LipoSuction Surgery; 1987 Febr; Los Angeles.

4. Casteilla L, Charrière G, Laharrague P, Cousin B, Planat-Benard V, Pericaud L, Chavopin JP. Tissus adipeux, chirurgie plastique et reconstructrice: le retour aux sources. Ann Chirurg Plastiq Esthétiq. 2004; 49(5):409-18.

5. Zuk PA, Zhu M, Mizuno $H$, Huang J, Futrell JW, Katz AJ et al. Multilineage cells from human adipose tissue: implications for cellbased therapies. Tissue Eng. 2001; 7(2):211-28.

6. Baptista LS, Pedrosa CGS, Silva KR et al. Bone marrow and adipose tissue-derived mesenchymal stem cells: how close are they? J Stem Cells. 2007; 2: issue 2.

7. Robey $P G$, Bianco $P$. The use of adult stem cells in rebuilding the human face. J Am Dent Assoc. 2006: 137 (7):961-72.

8. Moseley TA, Zhu M, Hedrick MH. Adipose-derived stem and progenitor cells as fillers in plastic and reconstructive surgery. Plast Reconstr Surg. 2006; 118(3 Suppl):121S-128S.

9. Yoshimura K, Sato K, Aoi N, Kurita M, Hirohi T, Harii K. Cellassisted lipotransfer for cosmetic breast augmentation: supportive use of adipose-derived stem/stromal cells. Aesthetic Plast Surg. 2008; 32(1):48-55; discussion 56-7. Epub 2007 Sep 1.

10. Carruthers JDA, Carruthers A. Facial sculpting and tissue augmentation. Dermatol Surg. 2005; 31(11 Pt 2):1604-612.

11. Spees JL, Gregory CA, Singh H, Tucker HÁ, Peister A, Lynch PJ et al. Internalized antigens must be removed to prepare hypoimmunogenic mesenchymal stem cells for cell and gene therapy. Mol Ther. 2004; 9(5):747-56.

12. Salles AG, Lotierzo PH, Gemperli R, Besteiro JM, Ishida LC, Gimenez $\mathrm{RP}$ et al. Complications after polymethylmethacrylate injections: report of 32 cases. Plast Reconstr Surg. 2008; 121(5):1811-20.

13. Monheit GD, Coleman KM. Hyaluronic acid fillers. Dermatol Ther. 2006; 19(3):141-50
14. Massone C, Horn M, Kerl H, Ambros-Rudolph CM, Giovanna Brunasso AM, Cerroni L. Foreign body granuloma due to Matridex injection for cosmetic purposes. Am J Dermatopathol. 2009; 31(2):197-9.

15. Giordano A, Galderisi U, Marino IR. From the laboratory bench to the patient's bedside: an update on clinical trials with mesenchymal stem cells. J Cell Physiol. 2007; 211(1):27-35.

16. Watson D, Keller GS, Lacombe V, Fodor PB, Rawsley, lask GP. Autologous fibroblasts for treatment of facial rhytids and dermal depressions. A pilot study. Arch Facial Plast Surg. 1999; 1(3):16570 .

17. Boss WK Jr, Usal H, Chernoff G, Keller GS, Lask GP, Fodor PB. Autologous cultured fibroblasts as cellular therapy in plastic surgery. Clin Plast Surg. 2000; 27(4):613-26.

18. Weiss RA, Weiss MA, Beasley KL, Munavalli G. Autologous cultured fibroblast injection for facial contour deformities: a prospective, placebo-controlled, Phase III clinical trial. Dermatol Surg. 2007; 33 (3):263-8.

19. Stashower M, Smith K, Williams J, Skelton H. Stromal progenitor cells present within liposuction and reduction abdominoplasty fat for autologous transfer to aged skin. Dermatol Surg. 1999; 25(12):945-9.

20. Park BS, Jang KA, Sung JH, Park JS, Kwon YH, Kim KJ et al. Adipose-derived stem cells and their secretory factors as a promising therapy for skin aging. Dermatol Surg. 2008; 34(10):1323-6. Epub 2008 Jun 27

Recebido em 28/10/2008

Aceito para publicação em 30/12/2008

Conflito de interesse: nenhum

Fonte de financiamento: FAPERJ e CNPq

\section{Como citar este artigo:}

Silva CC, Baptista LS, Carias RBV, Menezes Neto HC, Borojevic R. Cultura autóloga de células-tronco mesenquimais de tecido adiposo para o tratamento de rítides faciais. Rev Col Bras Cir. [periódico na Internet] 2009; 36(4). Disponível em URL: http://www.scielo.br/rcbc

\section{Endereço para correspondência:}

César Claudio-da-Silva

E-mail: cesar@claudiodasilva.com 